\title{
Voluntary muscle strength in hemiparesis: distribution of weakness at the elbow
}

\author{
JG COLEBATCH, SC GANDEVIA, PJ SPIRA \\ From the Unit of Clinical Neurophysiology, Department of Neurology, The Prince Henry Hospital and School of \\ Medicine, University of New South Wales, Sydney, Australia
}

SUMMARY Maximal voluntary strength (torque) of the flexors and extensors of the elbow was measured in 56 normal subjects and 18 hemiparetic subjects. In normal subjects the ratio of extension to flexion strength averaged $55 \%$ and did not differ significantly between sides or sexes. The ratio of maximal extensor to flexor strength on the clinically unaffected side of hemiparetic subjects was the same as that for the normal subjects but it was significantly increased on the affected side. This increase indicates that the elbow flexors were relatively more weakened than the extensors on the hemiparetic side, a conclusion contrary to conventional clinical teaching. The increase in the ratio was not the result of co-contraction of either muscle group. A possible physiological basis for the observed distribution of weakness is suggested.

The "upper motor neuron" syndrome is believed to have certain characteristics which are independent of the exact site or type of lesion responsible. These include increased muscle tone, hyperreflexia and weakness. The weakness has long been considered to have a characteristic distribution (see, for example, refs 1,2 ). In the upper limb, the weakness is currently considered to involve distal more than proximal muscle groups and to be more marked in extensor muscles. In the lower limb, the flexor muscles are more severely affected than their antagonists. ${ }^{34}$ Despite these clinical observations, there have been no detailed measurements of the maximal voluntary strength of different muscle groups in upper motor neuron lesions.

The distribution of weakness in hemiparesis is believed to reflect the relative "potency" of the descending cortical projections to the various muscle groups, the most severe weakness occurring in those muscles with the most powerful descending inputs. Thus, the pattern of muscular weakness is important not only clinically, but also for understanding the distribution of descending motor outflow in normal man. This study was designed to compare the maximal voluntary strength of the extensors and flexors at the elbow, both in subjects with unilateral upper

Address for reprint requests: Dr SC Gandevia, Unit of Clinical Neurophysiology, The Prince Henry Hospital, PO Box 233, Matraville, Sydney 2036, Australia.

Received 19 November 1985.

Accepted 5 December 1985 motor neuron weakness and in normal subjects. The strength of the two muscle groups was measured on both sides. It was also expressed as a ratio to allow distinction between weakness which affected both groups of muscles equally and weakness which affected one group preferentially.

Some of these results have been reported previously in brief form. ${ }^{5}$

\section{Methods}

The maximal voluntary strength of elbow flexion and extension on both the right and left sides was measured in patients with unilateral weakness of the upper motor neuron type and in a group of normal subjects. Informed consent was obtained.

A total of 18 hemiparetic subjects was studied, eight males and 10 females, aged 22 to 80 years (mean age 59 ). Eleven were weak on the right side, the remainder on the left. The time from the onset of symptoms varied from 1 week to 48 weeks (table 1). Sixteen of the patients had acute onset of neurological deficit, presumed or proven to be of vascular origin while two subjects suffered from cerebral tumours (one primary and one metastatic). They were selected from outpatients attending the hospital rehabilitation department and inpatients at the time of study. Each hemiparetic subject fulfilled four criteria. First, there were typical features of an upper motor neuron syndrome affecting the upper limb, including increased tone, hyperreflexia and distal weakness. Several had a moderate sensory loss and all but two of the 18 had an extensor plantar response. Second, the weakness was strictly unilateral as assessed both subjectively and clinically. Third, the subjects had to be co-operative and have sufficient mobility at the shoulder to position their weak arm in the 
Table I Strength and duration of weakness for the 18 hemiparetic subjects. Results for extension and flexion are shown under " $E$ " and " $F$ " respectively. The duration of weakness is measured in weeks from the onset of the stroke except for two patients $\left(^{*}\right)$ with cerebral tumours in whom this is taken from the onset of symptoms. The ratio of extension to flexion strength for both sides is shown in the final column as a percentage. In 15 of the 18 patients the ratio was increased on the hemiparetic side indicating more severe weakness of the flexors (see text).

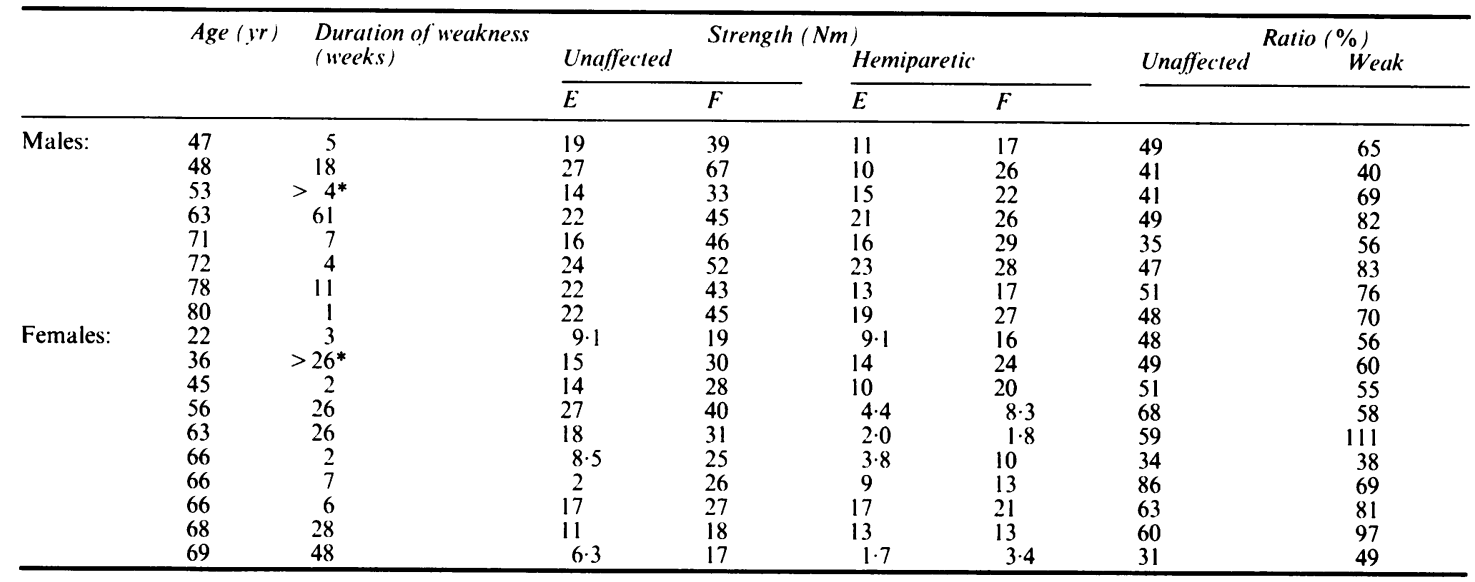

recording apparatus as well as some residual strength in both muscle groups acting about the elbow. Fourth, there was objective evidence of weakness on the clinically affected side, as defined by a measured reduction in strength of at least $10 \%$ compared with the unaffected side in one of the muscle groups acting at the elbow. Adoption of this last criterion led to the exclusion of some patients with otherwise typical hemiplegic features but with only distal weakness.

A group of normal volunteers was also studied to define the normal ratio of elbow extensor to flexor torque on each side and to test the assumption that this ratio was, on average, the same on both sides. The group consisted of 32 males (mean age 44 years, range 21-102) and 24 females (mean age 40 years, range 18-85). None had any history of neurological or other relevant illness.

The subjects were seated with the arm flexed at the shoulder and elbow with the forearm supinated and attached to an isometric myograph at the wrist. The angle at the elbow joint was $90^{\circ}$. This angle was selected because it represented the midrange of joint movement and was close to the angle at which strength is usually tested clinically. It is also a favourable angle in terms of the length-tension relationship for both muscle groups. ${ }^{6}$ Strain gauges connected to the base of the bar provided an output of torque (see also ref 7). The subjects were either instructed to flex or to extend their arms at the elbow maximally for a period of about $5 \mathrm{sec}$ onds. Each measurement was repeated at least three times with a rest period of 30 to 60 seconds between each observation. Measurements were then repeated on the other side. The largest peak during the series of contractions was taken to be the maximal strength. Flexion was usually tested before extension and, for the normal subjects, the first side to be tested was chosen randomly while for the patients the stronger (unaffected) side was studied first. All participants were encouraged throughout their efforts and usually had access to visual feedback. Under these conditions there is evidence that maximal voluntary activation of $\operatorname{limb}^{89}$ and respiratory muscles ${ }^{10}$ can be achieved during maximal "efforts" in normal subjects. Surface or needle electromyograms (EMG) were made in four of the patients using standard techniques. Interelectrode distance for surface EMG was 2-3 cm.

The ratio of the maximum extensor strength to the maximum flexor strength on each side was calculated and expressed as a percentage. An equal ratio on the two sides in a subject with hemiparesis would imply that both muscle groups had been affected to the same relative degree. A reduction in the ratio on the hemiparetic side would imply a greater weakness of extensors while an increase in the ratio would mean a greater relative weakness of flexors.

\section{Results}

\section{Normal subjects}

The elbow flexors were invariably stronger than the elbow extensors and males were stronger than females (table 2). The reduction of strength with age was modest. The subjects were grouped depending upon whether they were less than or greater than 60 years of age. Results for the elbow flexors and extensors of both sides have been combined for simplicity. (Paired $t$ tests indicated that there was no significant difference between the flexor and extensor strength on either side for any of the age groups except for the elbow flexors of females less than the age of 60 years).

The ratio of extensor to flexor strength did not vary significantly between sides nor, unlike absolute strength, between sexes (analysis of variance). The overall ratio of extensor to flexor strength for the normal subjects was $54.9 \pm 8.9 \%$ (mean \pm SD) with a significant correlation between the ratio on the right and left sides $(\tau=0.57)$. Linear regression of the ratio 
Table 2 Maximal strength (in Nm) of elbow extension and flexion strength for 56 normal subjects. Mean values with the standard deviations (in brackets) are given. The results for males and females, depending upon age, are shown separately. The values for the right and left sides have been combined. The right column shows the mean and standard deviation of the ratio of extensor to flexor strength expressed as a percentage for each group. This ratio did not differ significantly between any of the four groups

\begin{tabular}{llll}
\hline & Extension & Flexion & Ratio $(\%)$ \\
\hline Males $<60(\mathrm{n}=22)$ & $34 \cdot 3(6 \cdot 6)$ & $63 \cdot 8(11 \cdot 4)$ & $54 \cdot 1(8 \cdot 1)$ \\
Males $>60(\mathrm{n}=10)$ & $34 \cdot 6(10 \cdot 3)$ & $61 \cdot 2(14 \cdot 7)$ & $56 \cdot 6(10 \cdot 2)$ \\
All males & $34 \cdot 4(7 \cdot 9)$ & $62 \cdot 1(14 \cdot 1)$ & $54 \cdot 9(8 \cdot 8)$ \\
Females $<60(\mathrm{n}=17)$ & $19 \cdot 9(4 \cdot 0)$ & $36 \cdot 2(5 \cdot 6)$ & $55 \cdot 3(9 \cdot 1)$ \\
Females $>60(\mathrm{n}=7)$ & $16 \cdot 7(4 \cdot 7)$ & $32 \cdot 1(10 \cdot 8)$ & $54 \cdot 1(8 \cdot 9)$ \\
All females & $19 \cdot 0(4 \cdot 4)$ & $35 \cdot 0(7 \cdot 6)$ & $54 \cdot 9(9 \cdot 0)$ \\
All subjects: & & & $54 \cdot 9(8 \cdot 9)$ \\
\hline
\end{tabular}

against age showed no significant alteration with age. Measurements in four subjects on four separate occasions revealed no significant change in the ratio (or absolute strength) on repeated testing to suggest a learning effect. The coefficient of variation for the measurements in these four subjects was $4 \%$ for flexor strength and $12 \%$ for extensor strength and the ratio of extensor to flexor strength.

\section{Hemiparetic subjects}

On the hemiparetic side the ratio of extensor to flexor strength was increased compared with the clinically unaffected side in 15 of the 18 patients (figs 1 and 2). In two the ratio was reduced and in one it was unchanged (table 1). The mean increase in the ratio

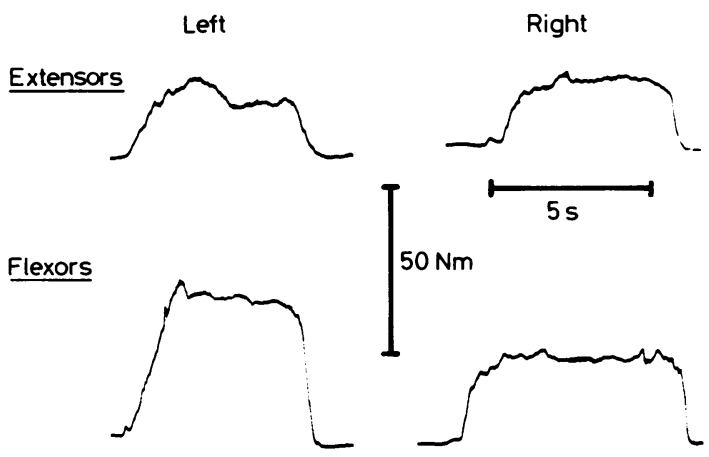

Fig 1 Measurements of maximal strength (torque) at the elbow, flexed to $90^{\circ}$, from a male subject with a right hemiparesis. Elbow extensor strength (above), flexion strength (below) measured in Newton-metres (Nm). The ratio of extensor to flexor torque was increased on the weak side, which indicated that the elbow flexors were relatively more affected than the extensors. This data is from one of seven subjects in whom the extensor strength was well preserved on the hemiparetic side.

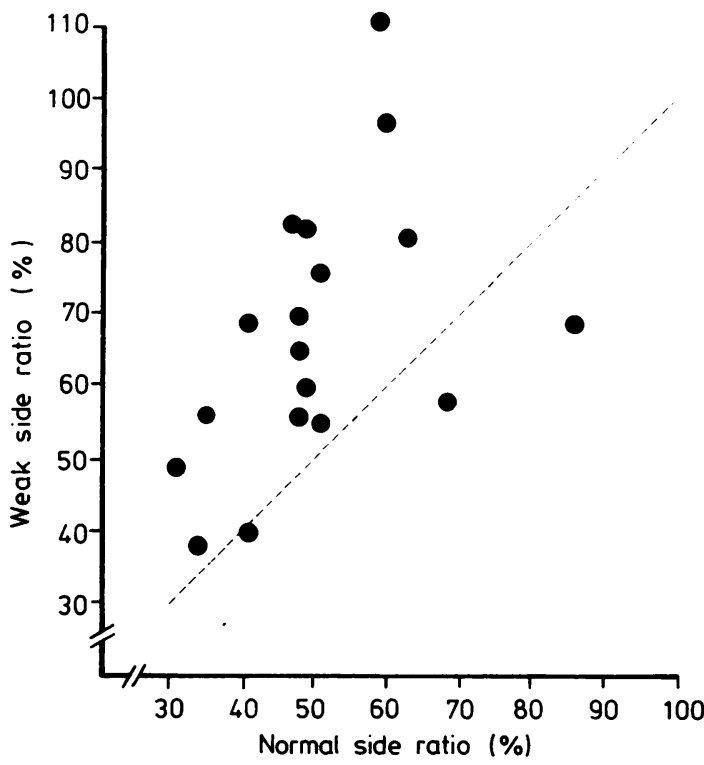

Fig 2 Ratios of extensor to flexor strength at the elbow on the normal and weak sides for all the hemiparetic subjects. The dotted line is the line of identity. All but three of the points lie above the line of identity. The ratio on the weak side was significantly increased for the group (paired t test, $p<0.01$ ).

between the two sides was $17 \%$ and was highly significant $(\mathrm{p}<0 \cdot 01$, paired $t$ test). This indicates that the reduction in strength in hemiparetic patients affected the elbow flexors to a relatively greater extent than the extensors. Surprisingly, in view of common clinical descriptions (see above), seven patients with otherwise typical upper motor neuron lesions had no weakness of the extensors of the elbow on the hemiparetic side, while the power of the flexors was reduced. No significant correlation was found between the difference in the ratio on the two sides and either the duration of the weakness or the degree of weakness (defined as the reduction in strength of the flexors). The ratio of the extensor to flexor strength on the clinically unaffected side did not differ from the results for the normal subjects $(0 \cdot 1>p>0.05$, unpaired $t$ test $)$. There was some reduction of strength in both muscle groups when compared with the results for the healthy control subjects. However, in only four hemiplegic subjects was strength more than two standard deviations from the mean (see Discussion).

Of the two patients with a reduction in the ratio of extensor to flexor strength on the weak side compared with the unaffected side, one had an unusually high ratio, $86 \%$, on the unaffected side. The other developed co-contraction of biceps brachii during 


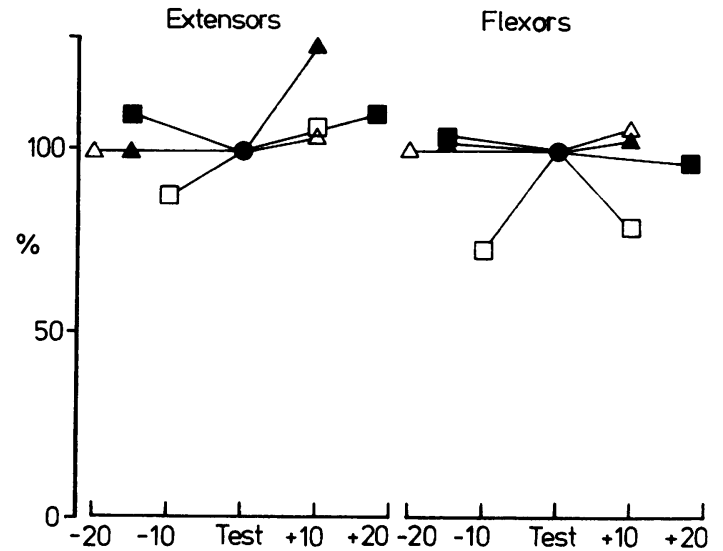

Fig 3 Length-tension relationships for the elbow extensors and flexors on the weak side of four hemiparetic subjects (each shown with a different symbol). Maximal torque is plotted as a percentage of that recorded at the usual test position $\left(90^{\circ}\right)$. Observations of both extensor and flexor maximal strength were repeated with the elbow more flexed and more extended (positive angles indicate extension). The only consistent finding was that extensor strength increased with greater degrees of elbow extension.

attempted extension on the affected side, but no cocontraction of triceps during flexion. This pattern of co-contraction would lead to underestimation of maximal extensor strength and therefore underestimation of the real ratio on the weak side. No other patient tested showed evidence of co-contraction of either muscle group during the maximal voluntary efforts.

The length-tension relationships of both flexors and extensors on the two sides were studied in a separate session in four patients using repeated maximal voluntary contractions. This required at least two maximal contractions in each of three positions for all four muscle groups and could only be undertaken in highly co-operative patients. In no patient could the difference in ratio on the two sides be explained by changes in the length-tension properties of the two muscle groups (fig 3 ). The only finding common to the weak side of all four patients was that the elbow extensors developed more torque (average increase $12 \%$ ) when more extended than when in the test position. In addition, these observations confirmed that the increase in the ratio of extensor to flexor strength in hemiparesis was reproducible.

\section{Discussion}

The distribution of weakness at the elbow joint was similar in 15 of the 18 patients with unilateral upper motor neuron lesions (hemiparesis). This supports the concept of a relatively uniform upper motor neuron syndrome. However, the data indicate that the conventional view of the distribution of weakness at the elbow is not correct as the flexor muscles were relatively more affected than the extensors in nearly all hemiparetic subjects. This conclusion applied both to hemiparetic subjects with recovering lesions (simple "strokes") and to those with progressive lesions such as cerebral tumours. It applied also to those hemiparetic subjects with the shortest duration of weakness (table 1).

The results obtained in normal subjects supported the approach adopted for the hemiparetic subjects, namely comparison of the ratio of the strength of the two muscle groups on the clinically affected and unaffected sides. This ratio was the same on each side in normal subjects and was independent of age or gender. The average value for elbow flexion torque, $62 \mathrm{Nm}$ for males and $35 \mathrm{Nm}$ for females, was almost twice the corresponding value for elbow extension torque in both sexes. The values reported here for maximal torque of elbow extensors and flexors, the ratio between them, and the relative strength of males and females are similar to previous reports. ${ }^{611-15}$ Control studies in the normal subjects showed that the maximal voluntary torques had an acceptable intra-subject variability and that they were not subject to any significant learning effect. The increase in the ratio of extensor to flexor torque was confirmed in four hemiparetic subjects in whom more extensive studies were conducted.

We attempted to exclude several pathophysiological abnormalities on the hemiparetic side which could have contributed to the results. Cocontraction of flexors and extensors occurred in only one of the hemiparetic subjects in whom electromyograms were recorded. During attempted flexion of the elbow by hemiparetic subjects Tang and Rymer $^{16}$ found no evidence of sustained triceps cocontraction. In the patient in whom co-contraction occurred in the present study it was present only during attempted extension and not during flexion. Thus, in this patient co-contraction would have tended to obscure the general trend observed for the ratio of extensor to flexor strength. The chronic change in resting muscle length which may result from assumption of the hemiplegic posture could have affected our results by resetting the length-tension properties of the muscle (for example, ref 17). Direct measurements of the voluntary length-tension relationship of both muscle groups suggested that any change in these properties was not responsible for the relative weakness of the flexor group. Histochemical and electrophysiological changes occur in motor units in hemiplegic patients, ${ }^{18-20}$ but the contraction properties of the whole muscle appear to be little affected. ${ }^{21}$ In addition, there was no correlation between the degree 
of selective weakness of the elbow flexors and the duration of the lesion. Such a correlation might have been expected if changes in motor unit properties were responsible.

Like many previous investigators, we have assumed that the clinically unaffected side in hemiparetic subjects was indeed normal. Contrary to this assumption, clinical observation ${ }^{22}$ and electrophysiological evidence $^{23}$ supports the presence of an ipsilateral corticospinal projection to muscles of the arm in man. The patients as a group were weaker in absolute terms on their clinically unaffected side than comparable normal subjects. The weakness was mild and only four patients had values more than two standard deviations from the mean for either of the muscles. The patients all stated that the clinically unaffected side seemed to have normal strength (a necessary condition for inclusion in this study). While the mild reduction in average strength could be taken as evidence of an ipsilateral effect, it could also reflect loss of power consequent upon reduced usage, particularly as the ratio of extensor to flexor strength was unaltered.

The basis for the clinical impression of predominant weakness of elbow extensors is not explained by this study. In clinical testing a mild reduction in flexor power may not be appreciated because it may still not be possible to "overcome" the flexor. Similarly, if the normal flexor power is underestimated then the flexor on the weak side will appear less severely affected. Inclusion of the elbow extensors in the groups of muscles said to be preferentially affected in hemiparesis may have occurred by default, simply because of the marked weakness of the extensors of the wrist and fingers in patients recovering from hemiplegia. These results also appear to contradict the clinical observation that elbow flexors recover from total paralysis before extensors. ${ }^{24}$ However, we did not study subjects in the earliest stages of recovery from hemiplegia as residual strength was required in both muscle groups for the test procedures. Our conclusions apply, however, to hemiparetic subjects with as much as $90 \%$ reduction in strength at the elbow compared to their normal side. The hemiplegic posture of flexion at the elbow is not contrary to the results presented here as this posture is not due simply to the strength of the muscles acting at the elbow, but to the effects of neck and labyrinthine reflexes. ${ }^{25}$

The reason that the weakness in hemiparesis occurs predominantly in the flexors rather than the extensors of the elbow is not clear. The finding is consistent with the observation that, in the baboon, motoneurons of elbow flexors receive more monosynaptic pyramidal excitation than do the extensors ${ }^{26}$ of ref 27 . Even if this is so, a lesion removing the same proportion of fibres innervating each motoneuron pool would be expected to leave the ratio of residual power unaltered. The corticospinal fibres which innervate antagonist muscle groups are probably intermingled and thus equally likely to be affected by pressure, oedema or ischaemia. However, if the corticospinal fibres for the elbow flexors were larger (on average) than the extensor fibres, then they may be more susceptible to a variety of pathological processes. ${ }^{28}$ Differences in average conduction time of corticospinal fibres to the flexor and extensor motoneurons of the forearm have been demonstrated, ${ }^{29}$ presumably confirming differences in mean fibre diameter.

This work was supported by the National Health \& Medical Research Council of Australia. We are grateful to Drs D Burke, D Gillies and I McCloskey for comments on the manuscript. Dr D Tracey kindly translated several articles.

\section{References}

${ }^{1}$ Wernicke C. Zur Kenntnis der cerebralen Hemiplegie. Berliner Klinische Wochenschrift. 1889;45:969-70.

${ }^{2}$ Mann L. Uber den Lähmungstypus bei der cerebralen Hemiplegie. Sammlung Klinischer Vorträge 1895;132 (Innere Medicin No 39):355-68.

${ }^{3}$ Bickerstaff ER. Neurological Examination in Clinical Practice. 3rd ed. Oxford: Blackwell, 1969:133.

${ }^{4}$ Lance JW, McLeod J. A Physiological Approach to Clinical Neurology. 3rd ed. London: Butterworths, 1981:33.

${ }^{5}$ Colebatch JG, Gandevia SC. Distribution of weakness between extensors and flexors in upper motor neurone lesions. Proceedings of the 29th International Congress of Physiology 1983;15:294.

${ }^{6}$ Singh M, Karpovitch PV. Isotonic and isometric forces of forearm flexors and extensors. $J$ Appl Physiol 1966;21:1435-7.

${ }^{7}$ Gandevia SC, McKenzie DK, Neering IR. Endurance properties of respiratory and limb muscles. Resp Physiol 1983;53:47-61.

${ }^{8}$ Merton PA. Voluntary strength and fatigue. $J$ Physiol (Lond) 1954;123:553-64.

${ }^{9}$ Belanger AY, McComas AJ. Extent of motor unit activation during effort. J Applied Physiol (Respiratory, Environmental and Exercise Physiology) 1981;51:1131-5.

${ }^{10}$ Gandevia SC, McKenzie DK. Activation of the human diaphragm during maximal static effects. $J$ Physiol (Lond) 1985;367:45-56.

${ }^{11}$ Elkins EC, Ledin UM, Wakim KG. Objective recording of the strength of normal muscles. Arch Phys Med 1951;32:639-47.

12 Provins KA, Salter N. Maximum torque exerted about the elbow joint. J Appl Physiol 1955;7:393-8.

${ }^{13}$ Bankov S, Jørgensen K. Maximum strength of elbow flexors with pronated and supinated forearm. Communications from the Danish National Association for Infantile Paralysis 1969: No 29.

${ }^{14}$ Ikai M, Fukunaga T. Calculation of muscle strength per 
unit cross-sectional area of human muscle by means of ultrasonic measurement. Internationale Zeitschrift für angewandte Physiologie 1968;26:26-32.

${ }^{15}$ Nygaard E, Houston M, Suzuki Y, Jørgensen K, Saltin B. Morphology of the brachial biceps muscles and elbow flexion in man. Acta Physiol Scand 1983;117:287-92.

${ }^{16}$ Tang A, Rymer WZ. Abnormal force-emg relations in paretic limbs of hemiparetic human subjects. $J$ Neurol Neurosurg Psychiatry 1981;44:690-8.

${ }^{17}$ Goldspink G, Tabary C, Tabary JC, Tardieu C, Tardieu G. Effect of denervation on the adaptation of sarcomere number and muscle extensibility to the functional length of muscle. $J$ Physiol (Lond) 1974;236:733-42.

${ }^{18}$ Edström L. Selective changes in the sizes of red and white muscle fibres in upper motor neurone lesions and Parkinsonism. J Neurol Sci 1970;11:537-50.

${ }^{19}$ Chokroverty S, Reyes MG, Rubino FA, Barron KD. Hemiplegic amyotrophy: muscle and motor point biopsy study. Arch Neurol 1976;33:104-10.

${ }^{20}$ Young JL, Mayer RF. Physiological alterations of motor units in hemiplegia. J Neurol Sci 1982;54:401-12.

${ }^{21}$ Ismail $\mathrm{HM}$, Ranatunga $\mathrm{KW}$. Isometric contractions of normal and spastic human skeletal muscle. Muscle Nerve 1981;4:214-8.

${ }^{22}$ Adams RD, Eecken HV. Motor paralysis. In: Petersdorf RG, Adams RD, Braunwald E, Isselbacher KJ, Martin
JB, Watson JD eds. Harrison's Principles of Internal Medicine 10th ed. New York: McGraw-Hill, 1983:88.

${ }^{23}$ Cowan JMA, Day BL, Marsden CD, Rothwell JC. Evidence for an ipsilateral pathway to forearm muscles in man. J Physiol (Lond) 1983;343:114-5P.

${ }^{24}$ Twitchell TE. The restoration of motor function following hemiplegia in man. Brain 1951;74:443-80.

${ }^{25}$ Denny-Brown D. The Cerebral Control of Movement Liverpool: Liverpool University Press 1966:137-8.

${ }^{26}$ Phillips CG, Porter $R$. The pyramidal projection to motoneurones of some muscle groups of the baboon's forelimb. Progr Brain Res 1964;12:222-45.

${ }^{27}$ Preston JB, Shende MC, Uemura K. The motor cortexpyramidal system: patterns of facilitation and inhibition on motoneurones innervating limb musculature of cat and baboon and their possible adaptive significance. In: Yahr MD, Purpura DP, eds. Neurophysiological Basis of Normal and Abnormal Motor Activities New York: Raven Press, 1967:61-74.

${ }^{28}$ Gasser HE, Erlanger $J$. The role of fiber size in the establishment of a nerve block by pressure or cocaine. Am J Physiol 1929;88:581-91.

${ }^{29}$ Kasser RJ, Cheney PD. Characteristics of corticomotoneuronal postspike facilitation and reciprocal suppression of emg activity in monkey. $J$ Neurophysiol 1985;53:959-78. 